\title{
Listen to ISO 9001:2015 for organizational competitiveness: Correlation between change management and improvement
}

\author{
Luis Miguel FONSECA \\ ISEP-IPP, Porto, Portugal \\ Imf@isep.ipp.pt \\ José Pedro DOMINGUES \\ ISEP-IPP, Porto, Portugal
}

\begin{abstract}
In their quest to achieve superior performance and business results, organizations have extensively adopted models such as ISO 9001 Quality Managements Standards. Research supports that Quality Management System brings significant benefits for organizations competitiveness and success and more than 1 million organizations of all activity sectors worldwide have implemented ISO 9001. In a world of increasingly complexity and interconnection, the revised ISO 9001:2015 International Standard aims to ensure that Quality Management Systems are flexible while remaining reliable. The concept of Change Management was introduced in the standard and Improvement can be achieved both in a continual/incremental mode (already present in the ISO 9001:2008 edition) and in a breakthrough change/disruptive mode (new in ISO 9001:2015). ISO 9001:2015 is now closer to Business Excellence Models, such as the EFQM, that highlight the need for agility and flexibility for enduring success. To access if organizations that have already implemented ISO 9001:2015 are indeed managing change and achieving improvement, and if there is a relationship between these two variables, a survey was held with IRCA ISO 9001 Registered Auditors on a worldwide basis. Sample normality was confirmed trough Kolmogorov-Smirnov Test and the hypothesis was tested by using Pearson Correlation coefficient. The findings show that the auditee organizations have positively implemented ISO 9001:2015 requirements on change management and improvement. There is also a strong positive correlation between change management and improvement, suggesting that the organizations that properly manage change by planning, designing, implementing, and controlling change in an effective and efficient way, demonstrate a higher level of performance and results improvement. These conclusions have significant implications for the Quality/Organizational Excellence Management Body of Knowledge, requiring a new way of thinking for 21st-century organizations and reinforced attention to change management processes and the skills needed by the Quality/Organizational Excellence Managers professionals, for their successful use.
\end{abstract}

Keywords: ISO 9001, business excellence, change management, quality management systems, improvement, competitiveness.

\section{Introduction}

The global interconnected and dynamic market economy of the $21^{\text {st }}$ century, is a challenge to organizations, as they aim to create, deliver and capture value. Dimensions such as the external global environment (e.g., accessed by SWOT - strengths, weakness, opportunities and threats - and PESTEL - political, economic, social, technological, environmental and legal - Analysis), the external industry environment (e.g., accessed by SWOT and Porter competitive force model), the strategy of each organization (e.g., framed on Porter industry theory and/or Resourced based view theory) and random (luck) events that cannot be foreseen, are considered as the main factors that contribute to sustained organizational performance (Grant, 2010). 
In the quest to achieve superior performance and business results, more than 1 million organizations have adopted ISO 9001 Quality Managements Systems, on a worldwide basis, across all activity sectors, to help them to operate efficiently and respond to customer and key stakeholder requirements.

Research supports the view that Quality Management Systems (QMS) can bring significant benefits for organizations competitiveness and success, particularly when the motivation for its implementation are mainly internal (to change and improve), rather than just external (comply with customer demands, marketing visibility).

To ensure ISO 9001 remains updated, simultaneously reliable, and flexible, ISO has revised the International Standard, issuing ISO 9001:2015 edition September 2015.

Two of the major changes of the ISO 9001:2015 are the concepts of change management and improvement (previously continual improvement). Improvement can be achieved either by a continual mode, already present in the ISO 9001:2008 edition, or with a breakthrough change/disruptive mode, that is a novel approach in ISO 9001:2015. Excellent organizations achieve sustained outstanding results that meet both the short and the long-term needs of all their stakeholders and can identify and respond effectively and efficiently to opportunities and threats (EFQM, 2012). With the introduction of the concept of change management and the upgrading of continual improvement to improvement, ISO 9001:2015 is closer to Business Excellence Models, such as the European Foundation for Quality Management (EFQM) that highlight the need for agility and flexibility for enduring success (EFQM, 2012). From an organizational culture lens, ISO 9001:2015 has a stronger open systems approach (influence of the environment, dynamic perspective, need for survival) when compared with the previous ISO 9001:2008 version.

Considering that ISO 9001:2015 was released in September 2015, its time to access if organizations that have already implemented ISO 9001:2015 are indeed managing change and achieving improvement, and if there is a relationship between these two variables, e.g., do organizations that have high change intensity show higher improvement?

To test this hypothesis, a survey was held with IRCA ISO 9001 Registered Auditors. Sample normality was confirmed trough Kolmogorov-Smirnov Test and Descriptive statistics and Pearson Correlation analysis were used to test the research questions. The results are discussed and the conclusions underline the contribution of this research to knowledge concerning the application of ISO 9001:2015, change management, improvement and organizational competitiveness and excellence, while indicating eventual limitations and future lines of research.

\section{Literature review}

ISO 9001 International Standard has been adopted by more than 1 million organizations of all activity sectors, on a worldwide basis (ISO, 2016) and scholars have confirmed that ISO 9001 certification can have both internal and external benefits (Casadesús et al., 2000; Boiral, 2012; Tari et al.; 2012; Zimon, 2016) such as: improved productivity and efficiency; cost reductions; increased process and product quality; better internal controls, training, and communications; increased customer satisfaction; reduction in the number of complaints; less inspection; improved image, sales and market share.

Additional research supports the view that ISO 9001 implementation and subsequent certification improves overall performance (Corbett at al., 2005) and ISO 9001 QMS successful implementation is most significant when the motivations are internal rather 
than external and when the standard is interpreted and used as a companywide management improvement approach (Fonseca, 2015a). Yin and Schmeidler (2009) concluded that standardized management systems may be implemented in very different ways depending on organizations, which might explain some heterogeneous performance organizations that apply them.

There is investigation supporting the existence of positive relationships between ISO 9001 certification maturity and business excellence models such as the EFQM model, due to the adoption of common quality management principles, highlighting the value of ISO 9001 as a step towards excellence (Fonseca, 2015b). EFQM (EFQM, 2012) defines excellent organizations "as the ones that achieve and sustain outstanding levels of performance that meet or exceed the expectations of all their stakeholders". The EFQM Business Excellence Model $(2) 2013$ (EFQM, 2012) is based on the Fundamental Concepts of Excellence (foundation principles for achieving organizational excellence), on the Model Criteria (Enablers and Results, defining the underlying principles for achieving organizational enduring excellence) and the Radar (tool for driving systematic improvement in all areas of the organization). The EFQM Model also uses scoring matrices for Enablers and Results and is complemented with a global scoring range for the full model criteria, between 0 and 1000 points.

Concerning ISO 9001:2015 edition, it incorporates major changes when compared with the 2008 version (Fonseca, 2015a) and is closer to a Business Excellence Model:

- It is required that the organizations identify the external and internal issues that may impact its QMS ability to deliver its intended results. If there are changes in the context of the organization, in needs or trends, or in the relevant requirements of the relevant interested parties (those that influence the quality of their products and services), the organization's quality policy need to be reviewed, and the QMS changes should be planned and implemented;

- There is a stronger focus on process approach and intended results;

- The concepts of change and knowledge management have been introduced. Changes need to be managed both at strategic and the operational level, across the organization, and those that are necessary to ensure that products or services continue to meet their specified requirements need to be controlled. The objectives to be achieved with the changes must be defined, the positive (and negative) implications identified, and the impacts should be accessed. It should be confirmed that the necessary resources and organizational knowledge are available and that the QMS integrity is checked and assured;

- There is now "Improvement", instead of "Continual improvement" (incremental improvement). Examples of improvement can include correction, corrective action, continual improvement, breakthrough change, innovation, and re-organization (ISO, 2015).

Organizational culture should be dynamic and renewable (Jacobs and Christe-Zeyse, 2013), but organizational change is risky and multifaceted, and its success is dependable in the external environment and the internal dynamics of organizations (Jacobs et al. 2013). ISO 9001:2015 is in line with this approach (Fonseca, 2015c), by adding a stronger open systems perspective (influence of the environment, dynamic environment, need for survival). when compared with international standard 2008 edition, more based on natural systems views (follow rules and processes). 
It is also required that change management is addressed in a systemic way (Maes and Hootegem, 2011) and in a controlled process (Burke, 2008), as ISO 9001:2015 prescribes it, through the effective application of the Quality Management System, including processes for improvement of the system, and the assurance of conformity to customer and applicable statutory and regulatory requirements (ISO, 2015).

Bratianu and Amza (2009) have also remarked that managing change is associated with the implementation of innovations (and improvements), and that managing innovation and managing change are inter-related, and have major strategic relevance for organizational success, indicating a relationship between change management and the capability to innovate and improve.

The existing relationship between ISO 9001 and EFQM Business Excellence Model (Fonseca, 2015c) has been reinforced due to ISO update of the quality management principles (QMPs). The seven QMPS that support ISO 9000 and ISO 9001 quality management standards are now further matched with the EFQM Business Excellence Model principles, as summarized in table 1:

Table 1. ISO 9001: 2008 versus ISO 9001:2015 versus EFQM Model (2013)

\begin{tabular}{|c|c|c|}
\hline $\begin{array}{l}\text { ISO 9001:2008 Quality } \\
\text { Management principles }\end{array}$ & $\begin{array}{c}\text { ISO 9001:2015 Quality Management } \\
\text { principle }\end{array}$ & $\begin{array}{l}\text { EFQM Business Excellence Model } \\
\text { (2013) Fundamental concepts }\end{array}$ \\
\hline Customer Focus & Customer focus & Adding value for customers \\
\hline Leadership & Leadership & $\begin{array}{l}\text { Leading with vision, inspiration \& } \\
\text { integrity }\end{array}$ \\
\hline Involvement of People & $\begin{array}{l}\text { Engagement of people (stronger } \\
\text { than involvement }+ \text { focus on } \\
\text { competence) }\end{array}$ & $\begin{array}{l}\text { Succeeding through the talent of } \\
\text { people }\end{array}$ \\
\hline $\begin{array}{l}\text { Process Approach + System } \\
\text { Approach to Management }\end{array}$ & $\begin{array}{l}\text { Process Approach (a system is the } \\
\text { management of inter-related } \\
\text { processes, so system approach is now } \\
\text { its included under process approach) }\end{array}$ & $\begin{array}{lrr}\text { Sustaining outstanding results } \\
\text { (emphasis on enduring and } \\
\text { exceptional performance and results) }\end{array}$ \\
\hline $\begin{array}{l}\text { Factual Approach to Decision } \\
\text { Making }\end{array}$ & $\begin{array}{l}\text { Evidence-based decision making (full } \\
\text { facts are not always available in the } \\
\text { decision timing) }\end{array}$ & Managing with agility \\
\hline Continual Improvement & $\begin{array}{l}\text { Improvement } \\
\text { organizations are improvement } \\
\text { focused) }\end{array}$ & $\begin{array}{l}\text { Harnessing creativity \& innovation } \\
\text { (value and performance created } \\
\text { through continual improvement and } \\
\text { systematic innovation by harnessing } \\
\text { the creativity of their stakeholders) }\end{array}$ \\
\hline $\begin{array}{l}\text { Mutually Beneficial Supplier } \\
\text { Relationships }\end{array}$ & $\begin{array}{l}\text { Relationship management (stronger } \\
\text { stakeholder approach) }\end{array}$ & Developing organizational capability \\
\hline
\end{tabular}

Source: Authors' own research based in Fonseca (2015a and b) and EFQM (2013).

\section{Methodology}

Approximately 5000 auditors' contacts worldwide were retrieved from IRCA website and emails were send asking those auditors to respond to an online survey. The online survey is a suitable survey technique to reach a restricted population, used to on line activity and dispersed worldwide, when resources are limited and fast response times are demanded. However, on line web surveys pose some challenges such as overload of unsolicited emails that could generate low response rates when compared to other survey methods (Fan and Yan, 2010). 
IRCA Registered QMS Auditors certification requires auditors to meet a qualification criterion based on work and auditing experience, and successful completion of IRCA Certified Training Course (http://www.irca.org). By using independent and external auditors, the possible bias of studies using perceptual data based on quality managers' opinions is minimized.

After the initial questions designed to characterize the respondents, the questions, presented in table 2, were used to access auditors' agreement with a five-point Likert scale (Do not agree at all (1), ..., Totally agree (5):

Table 2. Survey questionnaire

Question
P1: Based on your ISO 9001:2015 audit experience, do you agree that "Change management"
has been successfully implemented by the auditee organizations?
P2: Based on your ISO 9001:2015 audit experience, do you agree that "Improvement" has
been successfully implemented by the auditee organizations?

Source: Authors' own research.

For the statistical treatment of data, Statistical Package for Social Sciences 20 (SPSS) was used. The research hypothesis (is there a relationship between the successful implementation of change management by ISO 9001:2015 certified organizations and their evidence of improvement?) was tested with correlation analysis. In case the data follows a normal distribution, Pearson correlation coefficient can be used. It measures the intensity of the relationship between ordinal variables and vary between -1 and 1 . As near the values are from these extremes the stronger is the linear association between the variables, with the sign indicating the direction of the association between $X$ (the independent variable) and $Y$ (the dependent variable). If $Y$ tends to increase when $X$ increases, the correlation coefficient is positive. If $\mathrm{Y}$ tends to decrease when $\mathrm{X}$ increases, the correlation coefficient is negative. If the value is zero, there is no linear relationship between the variables.

\section{Results and discussion}

The responses accounted for $7 \%$ of the population and the sample profile matched the population suggesting the sample is representative of the population. With almost $100 \%$ valid responses and electronic data treatment, data collection and processing errors were minimized. Approximately 65\% of the respondents developed auditing activities over the last 10 years (Figure 1) and had conducted at least one audit against the ISO 9001:2015 requirements (Figure 2). 


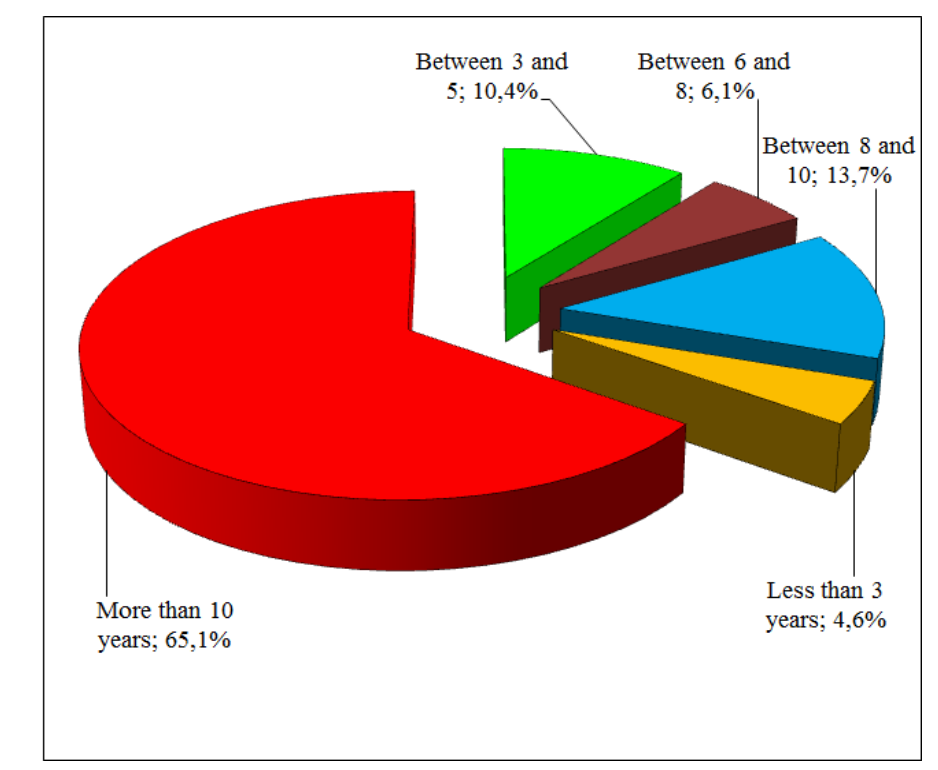

PICBE | 921

Figure 1. Auditors segmentation by year of experience

Source: Authors' own research.

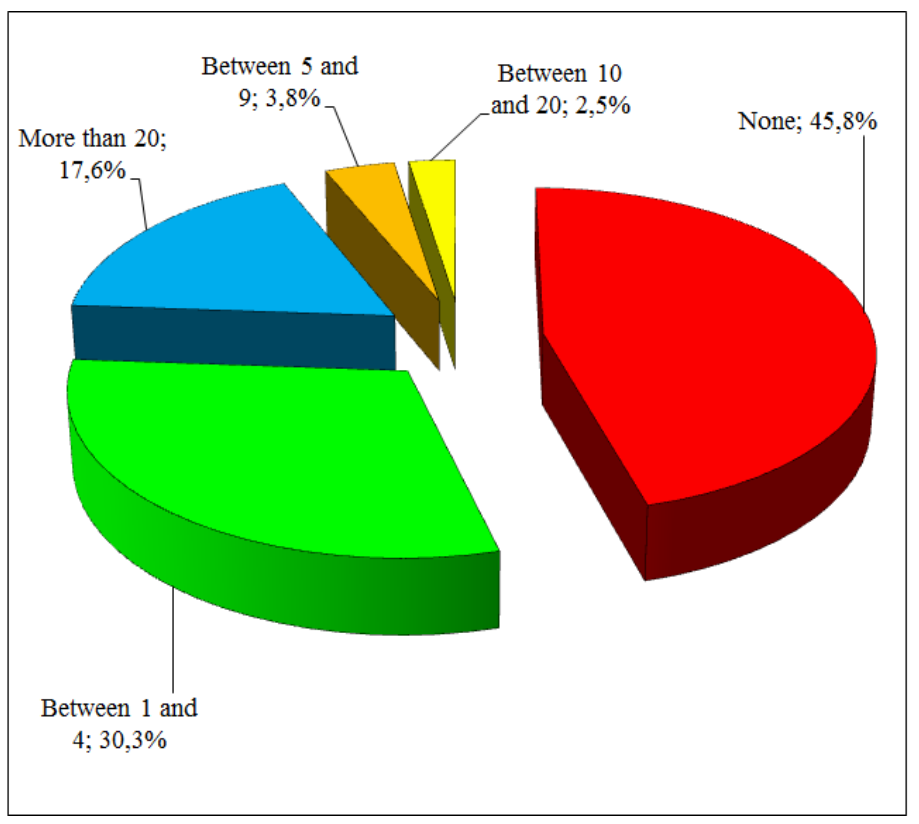

Figure 2. Auditors segmentation by the number of ISO 9001:2015 audits conducted so far year

Source: Authors' own research.

Geographically, Europe, East Asia and Pacific macro-regions yielded 57\% of total response, as shown in figure 3 presented below: 


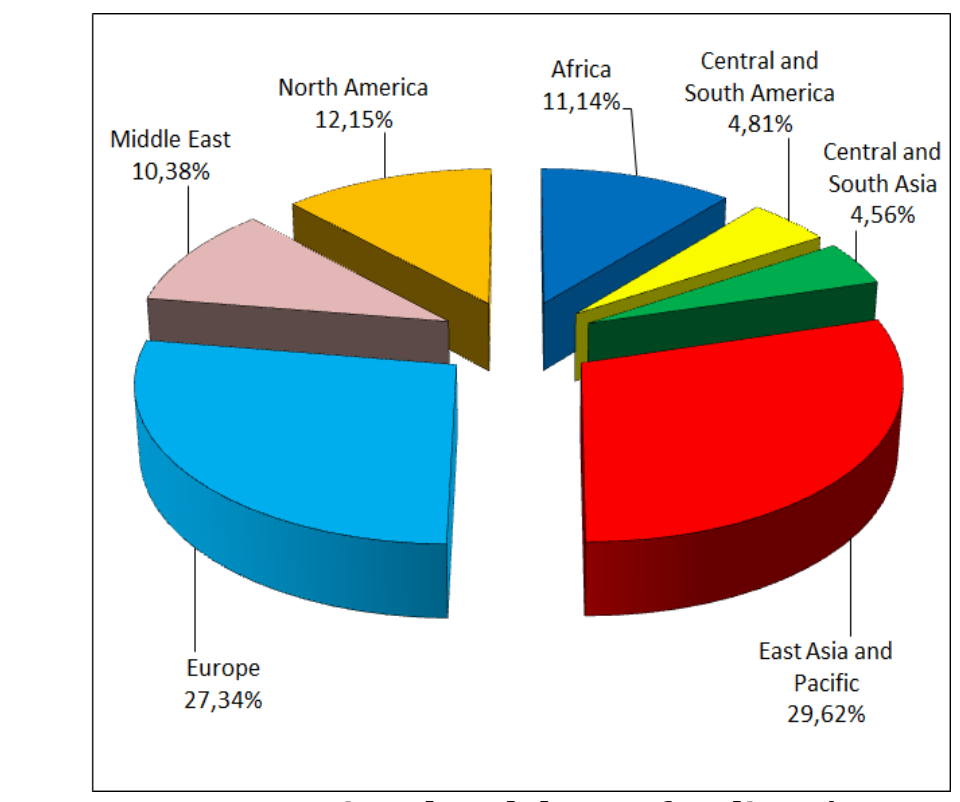

Figure 3. Macro regions breakdown of auditors' responses

PICBE | 922

Source: Authors' own research.

USA, UK, France, Australia, and Republic of Korea were the top five countries in the number of responses. The descriptive statistics of the survey results are presented in table 3:

Table 3. Descriptive statistics

\begin{tabular}{lll}
\hline Statistics & P1 (change) & P2 (improvement) \\
\hline Valid N & 298 & \\
Mean & 3,0268 & 3,1371 \\
Median & 3,0000 & 3,0000 \\
Mode & 3,0000 & 3,0000 \\
Standard Deviation & 0,89100 & 1,01561 \\
\hline
\end{tabular}

Source: Authors' own research.

These results indicate that for IRCA ISO 9001 QMS certified Auditors, organizations have implemented ISO 9001:2015 requirements on change processes and improving performance, in a mildly positive way, although there is some variation in auditors' responses, as shown in figures 4 and 5. 


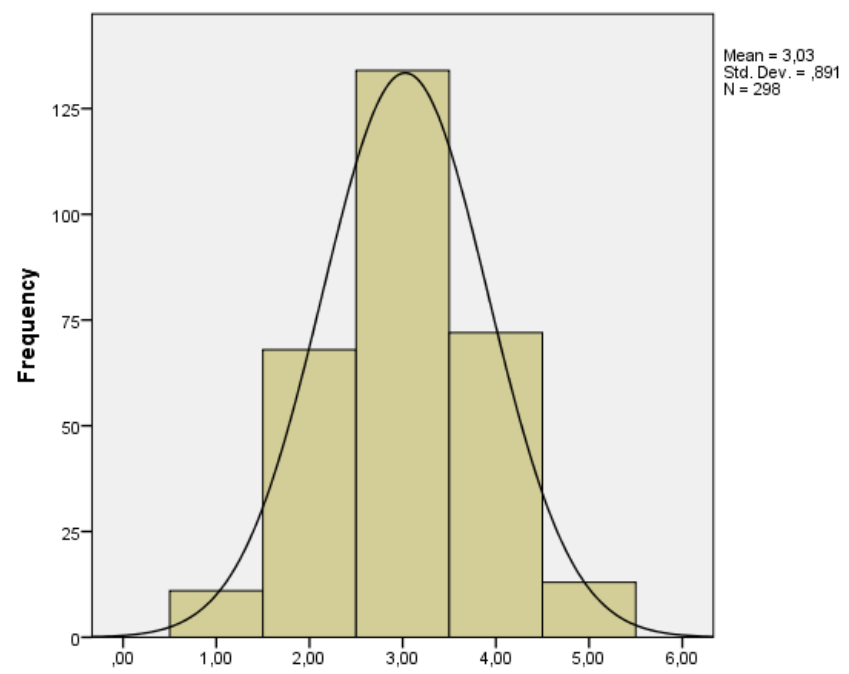

PICBE | 923

Figure 4. Successful implementation of "Change management" by ISO 9001:2015 auditee organizations

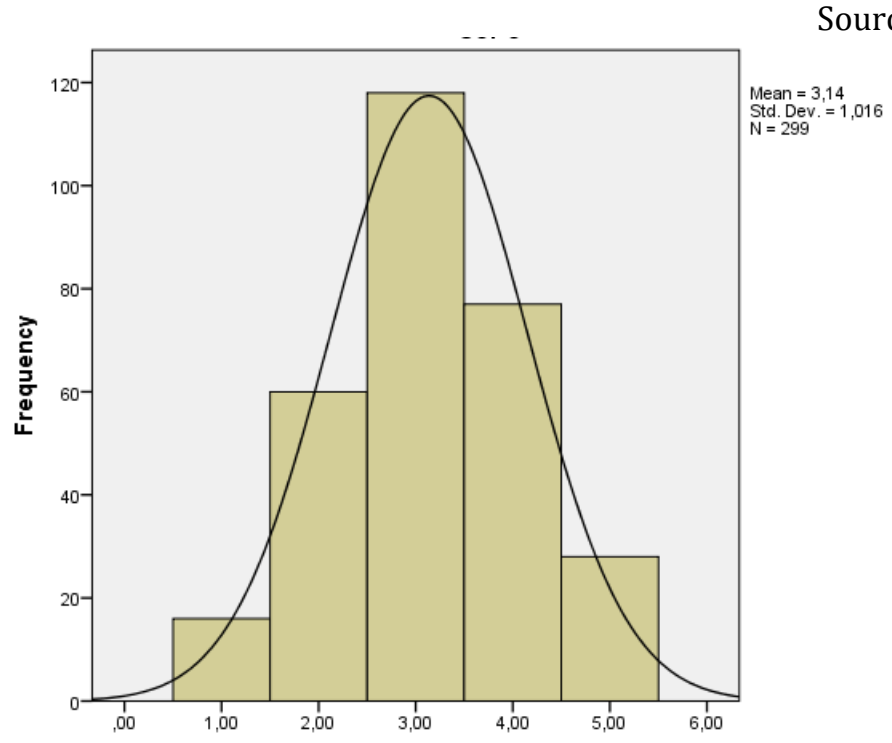

Source: Authors' own research.

Figure 5. Successful implementation of "Improvement" by ISO 9001:2015 auditee organizations

Source: Authors' own research.

Kolmogorov-Smirnov Test was used to confirm samples normality, as presented in table 4:

Table 4. One-Sample Kolmogorov-Smirnov Test

\begin{tabular}{|c|c|c|}
\hline Statistics & P1 (change) & P2 (improvement) \\
\hline $\mathrm{N}$ & 298 & 299 \\
\hline Normal Parameters ${ }^{\mathrm{a}, \mathrm{b}}$ Mean & 3,0268 & 3,1371 \\
\hline Normal Parameters & 0,89100 & 1,01561 \\
\hline Most Extreme Differences Absolute & 0,227 & 0,203 \\
\hline Most Extreme Differences Positive & 0,227 & 0,203 \\
\hline Most Extreme Differences Negative & $-0,233$ & $-0,192$ \\
\hline
\end{tabular}




\begin{tabular}{lll} 
Test Statistic & 0,227 & 0,203 \\
Asymp. Sig. (2-tailed) & $0,000^{c}$ & $0,000^{c}$ \\
\hline
\end{tabular}

Since the data follows a normal distribution, Pearson correlation coefficient was used to access the relationship between the variables. Table 5 summarizes the achieved results:

Table 5. Pearson correlations

\begin{tabular}{lll}
\hline Statistics & P1 (change) & P2 (improvement) \\
\hline P1 (change) Pearson Correlation & 1 & $0,617^{* *}$ \\
P1 Sig. (2-tailed) & & 0,000 \\
N & 298 & 293 \\
P2 (improvement) Pearson Correlation & $0,617^{* *}$ & 1 \\
P2 Sig. (2-tailed) & 0,000 & \\
N & 293 & 299 \\
\hline
\end{tabular}

PICBE | 924

Source: Authors' own research.

These results support the existence of a positive correlation between the successful implementation of change management (planning, designing, implementing, and controlling change) by ISO 9001:2015 certified organizations and their ability to implement and achieve improvements.

\section{Conclusion}

Due to the dynamic and inter-connected internal and external environments, there is an increased organizational challenge, to consistently meet customers and statutory/regulatory requirements, and simultaneously addressing the actual and future needs and expectations of relevant stakeholders (those that influence the quality of their products and services). Based on this research results, organizations need to effectively manage change to be able to effectively respond to changing environments and needs and to improve their processes and business results. ISO 9001:2015 edition is closer to a Business Excellence Model, by highlighting the need for managing change and improve, and has a stronger open systems approach (influence of the environment, dynamic perspective, need for survival) when compared with the previous ISO 9001:2008.

The research results show that according to IRCA ISO 9001:2015 QMS registered auditors, organizations have fairly successful implemented the Change Management and Improvement ISO 9001:2015 requirements, and there is a strong positive correlation between change management and improvement. These conclusions suggest that the organizations that properly manage change by planning, designing, implementing, and controlling change (originated from internal and external issues) in an effective and efficient way, demonstrate a higher level of performance and results improvement.

The use of improvement approaches, such as breakthrough change, innovation, reorganization, correction, and continual improvement, are relevant approaches for organizations to achieve business excellence. Organizations need to adopt adequate business models, and ensure they have the adequate organizational knowledge to successfully manage change and achieve improvement, as they need to respond to external and internal environment challenges, and foster business excellence to achieve superior results. The Quality and Organizational Excellence professionals also need to master the change management and improvement approaches, techniques, and tools. 
The use of IRCA QMS ISO 9001:2015 certified auditors, on a worldwide basis, assures the respondents are properly qualified and independent from the organizations that have implemented ISO 9001:2015, minimizing the possible bias of other studies based on quality managers' opinions. However, there are limitations of this research that need be recognized. The sampling frame was restricted to QMS certified auditors on IRCA public data base and the response rate is lower than those reported in other studies using web based surveys (Fan and Yan, 2010). In addition, since the auditors' feedback was based on half a year of ISO 9001:2015 application, future more in-depth and continuous studies should be performed, to ascertain the validity of these research results.

\section{Acknowledgements}

José Pedro Domingues is supported by FCT Post-Doc Grant Reference SFRH/BPD/103322/2014.

\section{References}

Boiral, O. (2012). ISO 9000 and organizational effectiveness: A systematic review. Quality Management Journal, 19 (3), 16-37.

Bratianu, C. \& Amza, V.D. (2009). A strategic perspective on managing innovation and change. Metalurgia International. 14(1), 68-71.

Burke, W. W. (2008). Organization Change Theory and Practice. Sage. ISBN-13: 9781412926706.

Casadesús, M., Heras, I. \& Ochoa, C. (2000). The benefits of the implementation of ISO 9000 normative: Empirical research in the Spanish companies. Proceedings of the Fifth world conference on production and operations management [CD-ROM].

Corbett, C.J., Montes-Sancho, M.J. \& Kirsch, D.A. (2005). The Financial Impact of ISO 9000 Certification in the United States: An Empirical Analysis. Management Science, 51 (7), 1046-1059.

EFQM, 2012. EFQM Excellence Model, Your Guide to the Model 2013, Brussels: EFQM.

Fonseca, L. (2015a). From Quality gurus and TQM to ISO 9001:2015: a review of several quality paths. International Journal for Quality Research, 9 (1), 167-180.

Fonseca, L.M. (2015b). Relationship between ISO 9001 certification maturity and EFQM Business Excellence Model results. Quality, Innovation and Prosperity, 19(1), 85-102.

Fonseca, L.M. (2015c). ISO 9001 quality management systems through the lens of organizational culture. Quality - Access to Success, 16 (148), 54-59;

Ghinea, V.M. (2015). Organizational Culture Dynamics. A Critical Overview of the Organizational Culture. Quality - Access to Success, 16 (145), 72-78.

Grant, R.M. (2010). Contemporary Strategy Analysis. John Wiley and Sons Ltd. ISBN: 978-1119-94188-0.

International Organization for Standardization, (2015). ISO 9001:2015 - Quality management systems - Requirements.

International Organization for Standardization. (2016). ISO Survey 2015(http://www.iso.org, accessed 2016.12.05).

Jacobs, G., van Witteloostuijn, A. \& Christe-Zeyse, J. (2013). A theoretical framework of organizational change. Journal of Organizational Change Management, 26 (5), 772 792. 
Maes, G. \& Hootegem, G. (2011). Toward a dynamic description of the attributes of organizational change. Research in Organizational Change and Development. 19, 121231.

Tarí, J.J., Molina-Azorín, J.F. \& Heras, I. (2012). Benefits of the ISO 9001 and ISO 14001 standards: A literature review. Journal of Industrial Engineering and Management, 5 (2), 297-322.

PICBE | 926

Yin, H. \& Schmeidler, P.J. (2009), Why do standardized ISO 14001 environmental management systems lead to heterogeneous environmental outcomes? Business Strategy and the Environment, 18, pp. 469-486.

Weimiao F., Yan Z.Y. (2010). Factors affecting response rates of the web survey: A systematic review. Computers in Human Behavior, 26, pp. 132-139.

Zimon, D. (2016). Influence of Quality Management System on Improving Process in Small and Medium--Sized Organizations. Quality - Access to Success, 17 (150), 61-64. 